\title{
Girişimcilerin E-Ticarete Yönelik Görüşlerinin İncelenmesi: Aksaray İli Örneği
}

DOI: 10.26466/opus.567860

\author{
Sefik Özdemir* \\ * Dr, Öğr. Üyesi, Aksaray Üni., Sağlık Bilimleri Fak. Merkez / Aksaray/ Türkiye \\ E-Posta: sefikozdemir@aksaray.edu.tr \\ ORCID: 0000-0003-3005-0570
}

$\ddot{O} z$

Bilgi teknolojilerinin hızlı bir şeklide gelişmesi önceden olmayan birçok yeniliğ̈in ortaya çıkmasını sağlamıştır. Girişimciliğin yeniden dizayn edilmesine ve başka bir perspektif kazanmasına neden olan en önemli yeniliklerden birisi e-ticarettir. Bu çalışma e-ticaret yapmayan girişimcilerin e-ticarete yönelik farkındalıklar ile eticaret yapan girişimcileri e-ticaret yapmaya iten nedenler ve e-ticaretten fayda sağlayıp sağlamadıkların ortaya koymayı amaçlamaktadır. Bu kapsamda Aksaray ilinde faaliyet gösteren girişimcilerden anket vasıtasıyla veri toplanmıştır. Toplanan verilerin analizi SPSS 20.0 programı ile yapılmıştır. Elde edilen sonuçlara göre girişimcilerin önemli bir kısmının e-ticaretin avantajlar sağladı̆̆ını ve başarılı olabilmeleri için gelecekte daha da önemli bir yer edineceğini bildikleri tespit edilmiştir. Yine e-ticaret yapan girişimcileri, eticaret yapmaya iten en önemli nedenler olarak müşteri hizmetlerini geliştirmek $(\% 74,2)$, müşterilerle diyaloğa girebilmek $(\% 67,7)$ ve küresel pazarlara erişebilmek $(\% 58,0)$ olduğu tespit edilmiştir. Analizler neticesinde ayrica girişimciler için e-ticaretin en çok "yurt içinden yeni müşteriler bulma" (\%71) ve "etkili reklam ve marka hizmeti oluşturma" $(\% 70,9)$ konularında fayda sağladı̆̆ı tespit edilmiştir.

Anahtar Kelimeler: Girişimci, E-ticaret, Girişimcilik 


\title{
Examining Entrepreneurs Opinions about E-Commerce: The Case of Aksaray
}

\begin{abstract}
Many innovations have been ensued from the rapid development of the information technologies. One of the most important of them that has caused entrepreneurship to be redesigned and gain another perspective is ecommerce. This research aims to find out the awareness of entrepreneurs that do not carry out e-commerce operations towards it, reasons that lead entrepreneurs with e-commerce operations to carry out them and if they profit from e-commerce. The data was collected from entrepreneurs that operate in Aksaray city through questionnaire. The data were analyzed with SPSS 20.0 program. According to the results, majority of the entrepreneurs acknowledge that e-commerce provides advantages and it will hold a more important place for success in the future. Moreover, the most important reasons that lead entrepreneurs to carry out e-commerce operations are improving relations with customers $(74,2 \%)$ and communicating with them $(67,7 \%)$ and reaching global markets $(58,0 \%)$. Results also indicate that e-commerce provides benefits for entrepreneurs mostly in finding new domestic customers $(71 \%)$ and creating effective advertisement and brand service $(70,9 \%)$.
\end{abstract}

Keywords: Entrepreneur, E-commerce, Entrepreneurship 


\section{Giriş}

İnternet, iş davranışlarını piyasaları, endüstrileri ve işletmeleri dönüştürmekte ve önemli ölçüde etkilemektedir. Çünkü bilgi teknolojisi artık işletmeleri ve pazarları yönlendirmektedir. Yeni ekonomi olarak adlandırılan bu süreçte, internet büyük bir öneme sahiptir. İnternet vasıtasıyla ticari işlemler kolaylaşarak güçlü ve her yerde faydalanılabilen bir mekanizma haline gelmektedir. Yeni ekonomi, yeni model ve paradigmaların kullanılmasının hayati olduğuna işaret etmektedir (Delone ve Mclean, 2004, s.31). Bu nedenle sürekli yenilenme, verimliliği arttırma ve çevresel talebe cevap verebilmek için kendilerini bilişim sektörünün yeniliklerine adapte eden işletme sayısı sürekli artış göstermektedir (Akın, 2005, s.4). Özellikle 1990'l y yllar ile birlikte sanal ortamda web tabanlı hizmetlerin artması, iş dünyası için değişimi kaçınılmaz kılmıştır. Çok hızlı bir gelişim ve dönüşüm içinde olan bu ortam girişimcilere birçok avantaj sağlamaktadır. Söz konusu avantajlardan birisi de e-ticaret olarak görülmektedir. Sanal ortamda iş ile ilgili gelişmelerin hacmi arttıkça e-ticareti bir seçenek olarak kullanan tüketicilerin ve işletmelerin sayısının arttı̆̆1 gözlenmektedir.

Birleşmiş Milletler Ticaret ve Kalkınma Konferansı'nın (UNCTAD) 2003'teki e-ticaret ve kalkınma raporuna göre bilgi ve iletişim teknolojisi, üretkenlik artışına olumlu katkı sağlamaktadır. Bilgi ve iletişim teknolojileri sayesinde işletmelerin daha rekabetçi hale geldiği, yeni pazarlara girme imkânı bulduğu ve yeni istihdam olanakları yarattığı belirtilmektedir. Bütün bunların, zenginlik ve sürdürülebilirliğin ortaya çıkmasına neden olarak ekonomik büyümeye çok önemli katkılar sağlaması beklenmektedir (Sebora, Lee ve Sukasame, 2009, s.303).

Dünyada faaliyet gösteren girişimcilerin çok önemli bir kısmı küçük veya orta ölçekli bir işletme kurarak ekonomiye katkı sağlamaktadırlar Bu durum ülkemiz için de geçerlidir. Türkiye İstatistik Kurumu (TUİK) verilerine göre; ülkemizdeki işletmelerin $\% 99,77$ 'si ve ihracatın $\% 60$ '1 KOBİlere aittir (Özeroğlu, 2018, s.66). Türkiye'de özellikle son yıllarda, hem ekonomik büyüme hem de istihdama önemli katkılar sağlayabilmek için girişimci sayısını ve KOBI'lerin e-ticaret hacmini arttırmaya yönelik politikalar hayata geçirilmektedir. Türkiye'de uygulanan politikalar, sahip olunan iklimsel özellikler, coğrafik konum ve genç nüfus gibi önemli 
avantajlar sağlayan birçok faktör olmasına rağmen girişimcilik ve e-ticaret kapasitesinin istenen ve beklenen seviyelere ulaşmadı̆̆ görülmektedir.

E- ticaret ağının sürekli genişlemesi ve gelecekte çok daha büyük bir yer edineceği düşünüldüğünde, Türkiye'de girişimcilerin bu duruma ilişkin farkındalıkları önemli hale gelmektedir. Bu nedenden dolayı bu çalışma e-ticaret yapmayan girişimcilerin e-ticarete yönelik farkındalıkları, e-ticaret yapan girişimcileri e-ticaret yapmaya iten nedenler ile e-ticaretten fayda sağlayıp sağlamadıklarını ortaya koymayı amaçlamaktadır. Bu kapsamda çalışmamızın birinci kısmında konu ile ilgili kavramsal çerçeve ve literatürde yer alan çalışmalara yer verilmiş olup ikinci kısmında girişimciler üzerine bir araştırma yer almaktadır. Daha sonra veri analizinin bulguları açıklanmaktadır. Son bölümde, çalışmadan elde edilen sonuçlar ile birlikte girişimciler için e-ticaret ile ilgili öneriler geliştirilmiştir.

\section{Girişimci ve E-ticaret}

Girişimcilik bireysel fayda elde edebilmek için çevredeki fırsatlardan etkin bir şekilde faydalanılarak bir işletmenin kurulmasıyla başlayan ve sonrasında ekonomik ve sosyal faydalar ortaya çıkmasına katkı sağlayan faaliyetler bütünü olarak tanımlanabilir. Türkoğlu vd., (2017) girişimciliği "girişimcinin riski üstlenip kar amactyla mal ya da hizmet meydana getirme faaliyeti" olarak tanımlamışlardır. Literatürde yapılan çalışmalar incelendiğinde girişimciliğin, istihdam, yeni iş oluşturma ve ekonomik büyümeyi olumlu yönde etkilediği görülmektedir (Özdemir vd., 2016, s.570). Girişimcilik faaliyetlerinin esas aktörü girişimcidir. Girişimcilik denince akla gelen ilk isimlerden birisi olan Joseph Schumpeter girişimciyi, yeni kombinasyonlar gerçekleştirerek pazarlara değişim uygulayan yenilikçiler olarak tanımlamaktadır. Bu yenilikler şu şekilde sıralanabilir (Ahmad ve Seymour, 2008, s.7):

- Yeni bir ürün veya daha kaliteli bir ürünün geliştirilmesi

- Yeni bir üretim yöntemi,

- Yeni bir pazarın açılmasi,

- Yeni bir arz kaynağının kullanılması

- İşin veya organizasyon süreçlerinin yeniden yapılandırılması 
Schumpeter' in tanımı bu nedenle girişimciliği iş anlamında inovasyonla eşit hale getirmektedir. Bu, pazar fırsatların belirlemek ve bunlardan yararlanmak için yenilikçi yaklaşımları kullanmak anlamına gelmektedir (Ahmad ve Seymour, 2008, s.8). Diğer bir ifadeyle girişimcilik faaliyetinde sadece yeni ve farklı olanı istemek yeterli değildir. İstenen yeniliklerin faaliyete geçirilmesi de gerekmektedir (Özdemir ve Kerse, 2018, s.15). Girişimciler çoğu zaman kendilerine güvenen, yüksek kazanç elde etmeyi amaçlayan ve değişime açık olan bireylerdir. Bu nedenle girişimcilerden hem bulundukları iş çevresini hem de küresel iş çevresini değerlendirerek ortaya çıan yenilikleri uygulamaları beklendiği söylenebilir. Ayrıca girişimcilerden hem maliyet hem de kar anlamında işletmelerine katkı sağlayacak yenilikleri takip etmeleri ve yeni müşteriler ve tedarikçiler bulmalarına yardımcı olabilecek her türlü bilgiyi önemsemelerinin beklendiği ifade edilebilir. Girişimcilerin iş süreçlerine söz konusu olumlu katkıları sağlayan en önemli faaliyetlerden birisi e-ticarettir.

Bilindiği üzere ticaret "mal veya hizmet satın alınması ve satılması" işlemlerini kapsayan bir süreç olarak ifade edilmektedir. Mal ve hizmetlerin fiziksel bir süreç olmadan satın alma veya satış işleminin internet aracılığıyla gerçekleştirilmesi e-ticaret olarak tanımlanabilir (Gökçen, 2007, s.258). Canpolat (2001) e-ticareti "tüketicilerin, işletmelerin ve kamu kurumlarmın elektronik ortamda (internet ya da intranet) yazı, ses ve görüntü şeklindeki sayısal bilgilerin işlenmesi, iletilmesi ve saklanması yoluyla, bilgilenmesi ve araştırma yapması, taahhüde girmesi, mal ve hizmetlerin müşteriye teslim edilmesi, bedelinin ödenmesi, satıs sonrası bakım ve destek hizmetlerinin yerine getirilmesi eylemleri süreci" olarak tanımlamıştır. Bu tanımlardan hareketle e-ticaretin internet ortamının pazar olarak kullanıldığı dünyanın en büyük pazar yeri olduğu söylenebilir. Burada müşteri olarak ulaşılmak istenen tüm gruplar, dünyanın her yerinde ulaşabileceğimiz bireyler olmaktadır.

20. yüzyılın sonlarına doğru ortaya çıkan e-ticaret, birçok kişiye göre matbaanın icadı veya endüstri devrimi kadar önemli bir gelişmedir ve en büyük teknolojik devrim olarak görülmektedir. Bu kişiler, e-ticaretin etkilerinin beklenenden çok daha fazla olacağını ileri sürmektedirler (Canpolat, 2001, s.12). Elektronik ticaret, insan yaşamının temelini değiştiren güçlü bir kavram ve süreçtir. Elektronik ticaret, bilgi teknolojileri devrimi ve ekonomi alanındaki iletişimin ana kriterlerinden 
biridir. Bu ticaret tarzı, insan için çok büyük faydalar sağlaması nedeniyle hızla yayılmıştır. Elektronik ticaretin geleneksel ticaretin sınırlamalarının çoğunu iptal ettiği kesin olarak iddia edilebilir. Örneğin, geleneksel ticaretin şekli ve görünümü temelden değişmiştir. Bu değişiklikler ekonomideki herhangi bir karar için temel oluşturmaktadır. Herhangi bir fiziksel alanı işgal etmeyen, erişim ve dolaşıma izin veren sanal pazarlara, dünyanın herhangi bir yerindeki marketlere evden ayrılmadan ulaşmak mümkündür. Dünyanın belirsiz bölgelerinde sanal vitrinlere yerleştirilen ve ayn zamanda sanal ağlarda reklam yapan ve elektronik hizmetler yoluyla ödeme yapılan malları seçme ve sipariş etme seçeneklerinin hepsini sunma fırsatı veren elektronik ticaret, bu yüzden yüzyılın mucizesi olarak görülmektedir (Nanehkaran, 2013, s.190). E-ticaret, işletmelerin ekonomik faaliyetlerinde köklü bir değişime neden olmuştur. Geçmişte yüz yüze ve kağıt tabanlı olan iş yapma şeklinin yerini web tabanlı elektronik sistemler almıştır. Girişimciler bu sayede büyük bütçeler ayırmadan küresel ölçekte işler ve yepyeni yaratıcı işler yapabilme imkânı yakalamışlardır (Elibol ve Kesici, 2004, s.304).

E- ticarette, rakiplerle eşit bir rekabet ortamında rekabet edilmektedir. Çünkü burada pazara girmek veya çıkmak girişimcinin kendisine bağlıdır. Diğer bir deyişle pazara giriş ve çıkışa yönelik herhangi bir engel bulunmamaktadır. Girişimciler için ulusal ve uluslararası piyasalara ulaşmanın bir aracı olan e-ticaret, aynı zamanda işletme maliyetlerinin azaltılarak daha fazla kar elde etme, müşterilere daha hızlı ve kaliteli ürün sunma ve yeni ürünler geliştirebilmeye imkan sağlamaktadır (Coşkun, 2004, s.250). Girişimcilerin çok önemli bir kısmının küçük ve orta ölçekli işletmelere sahip olması e-ticaret açısından önemli avantajlar sağlamaktadır. Küçük ve orta ölçekli işletmelerin esnek olan yapıları her türlü değişimi ve fırsatı daha hızlı bir şekilde uygulamasına olanak vermektedir. Bu yönüyle büyük ölçekli işletmelere nazaran sanal piyasada daha çok söz sahibi oldukları söylenebilir (İşler, 2008, s.288). Çevrimiçi ve e-ticaret sektöründeki söz konusu gelişmeler, küresel çevrimiçi pazardaki farklı toplulukları birbirine bağlamaktadır. Bu durum, birçok kuruluşun yerel müşterileri ve dünyadaki diğer potansiyel müşterilerle etkileşime girmeleri için kendi web sitelerini kurarak e-ticaret yapmalarını sağlamıştır (Qasim, Mohammed ve Liñán, 2018, s.419). 
Pazar ortamı rakiplerin, tedarikçilerin, satıcıların ve müşterilerin bir birleşimidir. Piyasadaki rekabetin varlığı satıcıları rakiplerinden bir adım önde olma konusunda motive eder. Rakipler pazarda girişimcileri zorlayan ana unsur olarak zorlayıcı rol aldıkları için girişimcilerin e-ticaret yapmalarında büyük bir rol oynamaktadırlar. Girişimcilerin, kendilerini benzersiz bir şekilde tanıtmak ve müşterilerin ürünlerini satın alabilmelerini sağlamak için işletmesine erişimi kolaylaştırmaları gerekmektedir (Qasim, Mohammed ve Liñán, 2018, s.422). Tüm bu nedenlerden dolayı eticaretin, girişimciler için artık vazgeçilemez faaliyetlerden birisi olduğu söylenebilir.

\section{Literatür İncelemesi}

E-ticaretin gelişmesini sağlayan en önemli faktör internettir. Bu bilgisayar aracılı ortam, işletmenin alıcı ile satıcı arasında nasıl işlem yaptığına dair derin etkilere sahiptir. İşlemin içeriği, fiziksel görünümü veya özellikleri yerine, ürün veya hizmetler hakkındaki bilgilere dayanması bakımından farklıdır. Böylelikle, birçok endüstride oyuncu olabilmek için bina ve makine gibi fiziksel bir altyapı olmadan bir bilgisayar ve iletişim platformu yeterli olmaktadır (Butler ve Peppard, 1998, s.601). Ülkemizde 2012 yılında \%45 olan internet kullanma oranı hızla yükselerek 2016 yılında \%58'e ulaşmıştır. 2014 yılı ile kıyaslandığında sadece iki yılda 6.6 milyon kişinin yeni internet kullanıcısı olduğu görülmektedir. Geleceğe dönük tahminlere göre ülkemizde 2020 yılında 62 milyon internet kullanıcısı olacağı ve internet kullanım oranının \%76'ya ulaşacağ $\mathrm{Bu}$ oranlara göre ülkemiz dünyanın en fazla internet kullanan ülkeler arasında 46.2 milyonluk internet kullanıcısıyla 17. Sirada, sosyal ağ kullananların sayısına göre 10. sırada yer almaktadır. Ayrıca ülkemizde 2021 yılı itibariyle nüfusun \%84'ünün akıllı telefon kullanıcısı olacağı tahmin edilmektedir (Kantarcı vd., 2017, s.41-43). Sarısakal ve Aydın (2003) mobil ve internet teknolojilerindeki gelişmelerin mobil ticaret kavramını ortaya çıkardığını ve günümüzde mobil araçların ticarette sıklıkla kullanıldığını ifade etmişlerdir. Araştırmacı, mobil ticaretin gelecekte daha fazla yaygınlaşacağını ve ticari anlayışı önemli ölçüde değiştireceğini belirtmektedir. 
İnternetteki en eski ve en popüler ticari etkinliklerden biri olan reklam ve tanıtım faaliyetleri, başlangıçta internet üzerinden düz metin mesajları gönderilerek gerçekleştirilirken (Poon ve Jevons, 1997, s.30) sonraki dönemde tedarik, satış ve e-işletmelere kadar varan geniş ve yaygın bir hizmet ağına ulaşmıştır. Literatürde işletmelerin internet ve e-ticaret erişimi ve bunların işletmelere sağladığı faydaları tespit etmeye yönelik birçok çalışma yapılmıştır (Dutta ve Evrard, 1999; Daniel vd., 2002; Premkumar and Roberts, 1999). Poon ve Jevons (1997) internet'in işletmelere sunduğu potansiyel faydaları ilk fark edenler arasında yer almaktadır. Bu araştırmacılar, internetin küçük işletmelere daha önce uygun olmayan ulusal ve uluslararası pazarlama kampanyalarına katılmaları için benzeri görülmemiş fırsatlar yarattığını belirtmişlerdir.

Falk ve Hagsten $(2015$, s.358) e-ticaretin mesafeyi problem olmaktan çıkardığını, daha düşük işlem maliyetlerine yol açtığını, bilgi toplanmasını kolaylaştırdığını, arz ve talebi birleştirdiğini ve aracılara ya da fiziksel varlığa olan ihtiyacı azalttığını belirtmektedirler. Alyoubi (2015, s.479) e-ticaretin özellikle gelişmekte olan ülkeler için, uzaktan sağlık bakımı ve eğitim gibi birçok yaygın soruna çözüm sunma potansiyeline sahip olduğunu ve dünyanın her yerinde işlerin yürütülmesinde bir devrime yol açtığın belirtmektedir. Yine Ueasangkomsate (2015) Taylandlı KOBİ'lerin hem ihracatçı hem de ihracatçı olmayan firmalara, e-ticaretin küresel pazara yüksek düzeyde büyük faydalar sağladığını ve günümüzde, e-ticaretin küresel ticaret için çok stratejik bir konumda olduğunu belirtmektedir. Diğer bir çalışmada Molla ve Heeks (2007) gelişmekte olan ülkelerdeki işletmeler için e-ticaretin sağladığı faydaları tespit etmişlerdir. Araştırmacıların tespit ettikleri söz konusu faydalar şunlardır:

- Gelir artış1

- İsslem maliyetlerinin azalması

- Satın alma maliyetlerinin azalmasi

- Artan müşteri sadakati ve müşteriyi elde tutma

- İndirimli pazarlama maliyetleri

- Tedarikçilerle ilişkilerin gelişmesi

- Genel memnuniyet

- Bilgiyi koruma maliyetlerinin azalmasi

- Hizmet farklılaşması 
- Müşteri ilişkilerinin gelişmesi

- Rekabetçi pozisyonun gelişmesi

- Pazar erişimini arttırma

- İşlem hızının gelişmesi

- Dış ilişkilerin gelişmesi

- Şirket imajının gelişmesi

- İç ilişkilerin gelişmesi

E-ticaret girişimcilerin başarısının yanı sıra küresel ticarette de çok önemli bir rol oynamaktadır. Bu yüzden Dünya Ticaret Örgütü (DTÖ) 2013 yılı forumunun odak noktasını, yeniliği ve dijital ekonominin büyümesini sağlamak için ülkelerin e-ticaret faaliyetlerini genişletmeleri olarak belirlemiştir. Elektronik ticaret, gelişmekte olan ülkelerdeki küçük ve orta ölçekli işletmeler (KOBİ'ler) için iş yaratma ve inovasyon için önemli bir araç haline gelmiştir. Yalnızca Çin'deki çevrimiçi ticaret, son on yılda \% 120 oranında büyümüştür. Benzer bir şekilde Latin Amerika'da e-ticaret, son on yılda 1,6 milyar ABD dolarından 43 milyar ABD dolarına yükselmiştir (Hussain, 2013). Türkiye'de e-ticaret pazarını uluslararası standartlara göre ölçümleyen Türkiye bilişim sanayicileri derneği (TÜBİSAD) “Türkiye e-Ticaret 2017 Pazar Büyüklügü̈" raporuna göre 2016 yılında 30,8 milyar TL olan e-ticaret hacmi 2017 yılında 42,2 milyar TL'ye ulaşarak \%37'lik bir büyüme sağlamıştır (Ulukan, 2018).

Gelişmekte olan ülkeler, e-ticaret için muazzam potansiyele sahip bir pazarı temsil etmektedir. Akademik araştırmalar genellikle e-ticaretten sağlam bir strateji olarak bahsetmekte ve bu ülkelerin yeni ekonomi modelinde kazanç elde edebilmeleri için ideal bir fırsat olarak değerlendirmektedir. Birleşmiş Milletler Kalkınma Programı (UNDP) buna örnek olarak verilebilir. UNDP'ye (2005) göre, gelişmekte olan ülkelerin, ekonomik ve sosyal gelişimlerini artıracak, ticari üretkenlik artışına yol açacak, işletmelerin maliyetlerini düşürecek ve uluslararası pazarlarla iç entegrasyon seviyesini artıracak şekilde, e-ticarete gönülden sarılmaları gerekmektedir (Alyoubi, 2015, s.480).

Daniel ve Grimshaw (2002) İngiltere' de küçük ve büyük şirketlerin elektronik ticareti (e-ticaret) benimseme nedenlerini ve bu iki grup şirket tarafından e-ticaretin benimsenmesinden elde edilen faydaları karşılaştırdığı çalışmasında küçük ölçekli işletmelerin büyük ölçekli işletmelere göre en çok rakiplere cevap vermek, gelişmiş müşteri hizmetleri 
sağlamak ve tedarikçilerle ilişkileri geliştirmek için e-ticaret kullanımına yöneldiklerini ortaya koymuştur.

Aslan ve Özata (2007) KOBÍlerin bilgi teknolojisi kullanım düzeyi ile yenilikçilik, rekabet gücü ve pazarlama kapasitesi arasında pozitif ve anlamlı bir ilişki tespit etmişlerdir. Buna göre pazarlama kapasitesi ve yenilikçilik, girişimcilik kapasitesini pozitif ve anlamlı biçimde etkilemektedir. Aydın (2018) TRB1 bölgesi imalat KOBI'lerinde yürütülen web tabanlı e-ticaret faaliyetlerinin; sipariş/üretim miktarlarının artışında, ürün/hizmet tanıtımlarında ve satışında, iletişim maliyetlerinin azalmasında, yeni pazarlara girişlerinde önemli bir araç olduğunu tespit etmiştir. Marangoz (2011) ile Bakırtaş ve Tekinşen (2006) konu ile ilgili teorik bir çerçeve çizerek e-ticaretin girişimciler için birçok açıdan önemli faydalar sağlayacağını belirtmişlerdir. Yaralı ve Kırık (2017) e-ticaretin Çaykur ve Tesbihane firmalarının marka bilinirliliğini olumlu yönde etkilediğini bulgulamışlardır.

Ancak e-ticaretin firsatlarla dolu olduğu görüşünü benimsemeyen ve e-ticaretin gelişmekte olan ülkelerde, söylendiği gibi olumlu katkılarının olmadığını savunan araştırmalar da yer almaktadır. Örneğin Ray (2011, s.5) iletişimdeki ufak bir iyileştirmenin yanı sıra, yakın tarihli çalışmalar, gelişmekte olan ülkelerdeki işletmelerin e-ticaret teknolojilerinde kaydedilen ilerlemelerden faydalanmadıklarını ifade etmiştir. Yazar, e-ticaret teknolojilerinin, yabancı ülkelerin azgelişmiş ülkelerin pazarlarına erişmesine yardımcı olurken, lehine geri dönüş yapmadığını ve azgelişmiş ülkelerdeki işletmelerin pazar erişimini genişletmelerine yardımcı olmadığını ileri sürmüştür. Araştırmacı, araştırma literatüründe e-ticaret için ifade edilen iyimserliğin temelsiz olduğunu belirtmektedir.

Yine Molla ve Heeks (2007) Güney Afrika'da bulunan 92 işletme üzerinde yaptığ 1 araştırmada e-ticaretin faydalarının iletişimdeki ufak gelişmelerle sınırlı olduğunu, "pazara erişim, müşteri/tedarikçi bağlantıları veya maliyet tasarrufları ile ilgili daha stratejik faydaların olmadığını" tespit etmişlerdir. Söz konusu araştırmada e-ticaret'in işletme maliyetlerini, satın alma, işe alım, pazarlama veya bilgi koruma maliyetlerini azaltmadığını bulgulamışlardır. Araştırmacılar ayrıca, ankete katılan şirketlerin önemli bir çoğunluğunun (\%80'den fazla), e-ticaretin bir sonucu olarak artan gelir, gelişmiş tedarikçi ilişkileri veya müşteri sadakati 
ve müşteriyi elde tutma gibi stratejik faydalar sağlamadığını ortaya koymuşlardır.

Diğer bir araştırmacı grubunun odak noktası ise e-ticaretin uygulanabilirliği ile ilgili faktörler olmuştur. Örneğin Aksu ve Gürbüz (2018) hayvancılık sektöründeki e-ticaret engellerinin araştırılması ve ortaya konulması amacıyla yaptıkları araştırmada temel maliyetler, bilgisizliğe bağlı güvensizlik ve geleneksel yönteme güven olarak belirledikleri üç temel faktörün hayvancılık sektöründe e-ticareti engellediğini tespit etmişlerdir. Benzer bir şekilde Rahayu ve Day (2015) tespit ettiği bulgulara dayanarak, Endonezya'daki KOBI'ler tarafından e-ticaretin kabul edilmesinin, algılanan faydalar, teknolojiye hazır olma, sahiplerin yenilikçiliği, sahiplerinin bilgi teknolojileri deneyimi ve sahiplerinin bilgi teknolojileri kabiliyeti gibi çeşitli faktörlerden etkilendiğini ifade etmişlerdir.

Yukarıda yer alan literatür ve bu konudaki yaygın görüşler nedeniyle işletmelerin e-ticaret yapmaları gerektiği ile ilgili çevresel bir baskının oluştuğu söylenebilir. Bu baskının işletmeler tarafından çeşitli elektronik ticaret teknolojilerinin benimsenmesi üzerinde önemli bir etkisi olmaktadır (Kurnia vd., 2015). Tüm bunlara rağmen e-ticarete katılım hala yaygın olmamakla birlikte, büyük firmalar, yüksek verimli firmalar ve uluslararası deneyime sahip firmalar tarafından daha sık kullanılmaktadır (Falk ve Hagsten, 2015, s.368). Bu durum daha çok küçük ve orta ölçekli işletmelerin sahipleri olan girişimcilerin e-ticarete bakış açılarını, girişimcileri e-ticarete iten nedenler ve e-ticaretten fayda sağlayıp sağlamadıklarını önemli hale getirmektedir. Bu çalışma girişimcilerin elektronik ticareti kullanma durumları ve elektronik ticaretin girişimcilere sağladığı faydaları tespit etmek amacıyla gerçekleştirilmiştir. Bu anlamda çalışmamızın Türkiye'de e-ticaret literatürüne katkı sağlaması beklenmektedir.

\section{Yöntem}

\section{Örneklem ve Veri Toplama Araçlarn}

Bu çalışmada yer alan örneklem, kolayda örneklem yöntemiyle Aksaray il merkezinde girişimcilik yapanlar arasından seçilmiş olup veri toplamak 
için anket tekniği kullanılmıştır. Araştırmada veri toplamak için kullanılan anket Daniel ve Grimshaw (2002) ve Bellek'in (2016) araştırmalarında yer alan anketlerden yararlanılarak oluşturulmuştur.

\section{Araştırmanın Amacı}

$\mathrm{Bu}$ çalışma, Türkiye'de e-ticaret yapmayan girişimcilerin e-ticarete yönelik farkındalıkları ile e-ticaret yapan girişimcileri e-ticaret yapmaya iten nedenleri ve e-ticaretten fayda sağlayıp sağlamadıklarını ortaya koymayı amaçlamaktadır.

\section{Bulgular}

Çalışma kapsamında katılımcılardan toplanan verilerin analizinden elde edilen bulgular bu bölümde yer almaktadır. Çalışmada kullanılan ölçeklerin alfa katsayıları Tablo 1'de verilmiştir. İncelemeler sonucunda ölçeklerin geçerlilik ve güvenirliliklerinin yeterli düzeyde olduğu tespit edilmiştir.

Tablo 1. Güvenirlilik analizlerinin sonuçları

\begin{tabular}{lll}
\hline Ölçekler & Değişken Sayısı & Ölçeğin Alfa Katsayısı \\
\hline E-ticaret kullanımı & 10 &, 951 \\
\hline E-ticaret kullanım nedeni & 7 &, 902 \\
\hline E-ticaretin faydaları & 9 &, 947 \\
\hline
\end{tabular}

Tablo 1'e göre çalışmada kullanılan ölçeklerin alfa katsayıları anketimizin yüksek düzeyde güvenilir olduğunu göstermektedir. Katılımcıların demografik verileri Tablo 2'de gösterilmiştir.

Tablo 2'ye göre katılımcıların büyük çoğunluğu erkek girişimcilerden (\% 69,3) oluşmaktadır. Katılımcıların eğitim düzeylerine bakıldığında en çok lise $(\% 28,0)$ mezunu oldukları görülmektedir. Araştırma kapsamında katılımcılardan toplanan diğer bir veri girişimcilerin deneyim sürelerine yöneliktir. Tablo 2'deki verilere göre katılımcıların büyük çoğunluğu 1-5 yıl ve 11-15 yıl arasında girişimcilik deneyimine sahiptir 
Tablo 2. Katılımcilarin demografik verileri

\begin{tabular}{|c|c|c|c|}
\hline \multirow[t]{4}{*}{ Cinsiyet } & & Frekans & Yüzde \\
\hline & Kadın & 23 & 30,7 \\
\hline & Erkek & 52 & 69,3 \\
\hline & Toplam & 75 & 100,0 \\
\hline \multirow[t]{8}{*}{ Eğitim düzey } & & Frekans & Yüzde \\
\hline & İlkokul & 13 & 17,3 \\
\hline & Ortaokul & 11 & 14,7 \\
\hline & Lise & 21 & 28,0 \\
\hline & Ön lisans & 10 & 13,3 \\
\hline & Lisans & 13 & 17,3 \\
\hline & Lisansüstü & 7 & 9,3 \\
\hline & Toplam & 75 & 100,0 \\
\hline \multicolumn{2}{|c|}{ Girişimcilik Deneyimi } & Frekans & Yüzde \\
\hline & $1-5$ y1l & 25 & 33,2 \\
\hline & $6-10$ yil & 14 & 18,7 \\
\hline & $11-15$ yil & 20 & 26,7 \\
\hline & $16-20$ yil & 8 & 10,7 \\
\hline & 21 yıl ve üstü & 8 & 10,7 \\
\hline & Toplam & 75 & 100,0 \\
\hline
\end{tabular}

Katılımciların internet, ve e-ticaret kullanım durumlarını tespit etmek amacıyla toplanan veriler Tablo 3'de gösterilmiştir.

Tablo 3. Katılımcilarin internet ve e-ticaret kullanım durumlarn

\begin{tabular}{llll}
\hline & & Frekans & Yüzde \\
\hline İş yerinizde İnternet kullaniyor musunuz? & Evet & 60 & 80,0 \\
\cline { 2 - 4 } & Hayır & 15 & 20,0 \\
\cline { 2 - 4 } & Toplam & 75 & 100,0 \\
\hline İşletmenizde e-ticaret yapıyor musunuz? & & Frekans & Yüzde \\
\cline { 3 - 4 } & Evet & 31 & 41,4 \\
\cline { 2 - 4 } & Hayır & 44 & 58,6 \\
\cline { 2 - 4 } & Toplam & 75 & 100,0 \\
\hline & & Frekans & Yüzde \\
\hline & Toplam & 31 & 100,0 \\
\hline
\end{tabular}

Tablo 3'e göre katılımcıların \% 80'i işyerinde internet kullanmaktadır. Yine katılımcıların büyük bir kısmının e ticaret (\% 58,6) yapmadığı tespit edilmiştir. Araştırmanın birinci kısmı e-ticaret yapmayan girişimcilerin eticaret farkındalıklarını ölçmeye yöneliktir. Söz konusu durumun tespitine yönelik girişimcilerin ifadelere katılım düzeylerinin analizi neticesinde elde edilen bulgular Tablo 4 'te verilmiştir 
Tablo 4. E-ticaret yapmayan girişimcilerin e-ticaret farkındalıkları

\begin{tabular}{|c|c|c|c|c|}
\hline 总富 & 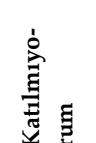 & 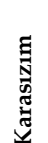 & 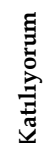 & 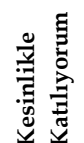 \\
\hline
\end{tabular}

\begin{tabular}{|c|c|c|c|c|c|c|c|c|c|c|c|c|}
\hline $\begin{array}{l}\text { E-ticaret yapmayan } \\
\text { girişimcilerin e-tica- } \\
\text { rete yönelik görüş- } \\
\text { leri }\end{array}$ & 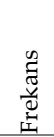 & $\begin{array}{l}\stackrel{0}{0} \\
\dot{2} \\
\end{array}$ & 宽 & $\begin{array}{l}\text { एँ } \\
\text { خ्रे }\end{array}$ & 跑 & $\begin{array}{l}\frac{8}{N} \\
\dot{y}\end{array}$ & 壳 & 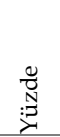 & 宽 & \begin{tabular}{l}
$\stackrel{0}{N}$ \\
\multirow{2}{*}{}
\end{tabular} & 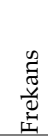 & 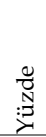 \\
\hline $\begin{array}{l}\text { İşletmeler gelecek } 5 \\
\text { yıl içerisinde E-Ti- } \\
\text { carete bağımlı hale } \\
\text { gelecektir. }\end{array}$ & 1 & 2,3 & 11 & 25,0 & 14 & 31,8 & 11 & 25,0 & 7 & 15,9 & 44 & 100 \\
\hline $\begin{array}{l}\text { E-Ticaret sayesinde } \\
\text { iş yapma hızı art- } \\
\text { maktadır }\end{array}$ & 3 & 6,8 & 5 & 11,4 & 6 & 13,6 & 15 & 34,1 & 15 & 34,1 & 44 & 100 \\
\hline $\begin{array}{l}\text { E-Ticaret sipariş, te- } \\
\text { darik, ödeme gibi } \\
\text { süreçlerin daha } \\
\text { hızlı gerçekleşme- } \\
\text { sini sağlamaktadır }\end{array}$ & 6 & 13,6 & 1 & 2,3 & 5 & 11,4 & 17 & 38,6 & 15 & 34,1 & 44 & 100 \\
\hline $\begin{array}{l}\text { E-Ticaret sayesinde } \\
\text { müşteri hizmetleri } \\
\text { iyileşmektedir. }\end{array}$ & 3 & 6,8 & 6 & 13,6 & 10 & 22,7 & 12 & 27,3 & 13 & 29,5 & 44 & 100 \\
\hline $\begin{array}{l}\text { E-Ticarete yapılan } \\
\text { yatırım, işletmele- } \\
\text { rin bilinirliğini ar- } \\
\text { tırmak açısından } \\
\text { çok önemlidir }\end{array}$ & 3 & 6,8 & 4 & 9,1 & 14 & 31,8 & 10 & 22,7 & 13 & 29,5 & 44 & 100 \\
\hline $\begin{array}{l}\text { E-Ticaret ile küresel } \\
\text { pazarlara daha ko- } \\
\text { lay ulaşılmaktadır. }\end{array}$ & 2 & 4,5 & 6 & 13,6 & 11 & 25,0 & 8 & 18,2 & 17 & 38,6 & 44 & 100 \\
\hline $\begin{array}{l}\text { E-Ticaret işletme- } \\
\text { lere rekabet üstün- } \\
\text { lügüü sağlamaktadır }\end{array}$ & 3 & 6,8 & 6 & 13,6 & 6 & 13,6 & 16 & 36,4 & 13 & 29,5 & 44 & 100 \\
\hline $\begin{array}{l}\text { E-Ticaret ulusal pa- } \\
\text { zarda yeni müşteri- } \\
\text { lere ulaşmamıza } \\
\text { katkı sağlar }\end{array}$ & 4 & 9,1 & 9 & 20,5 & 9 & 20,5 & 11 & 25,0 & 11 & 25,0 & 44 & 100 \\
\hline $\begin{array}{l}\text { E-Ticaret uluslara- } \\
\text { rası pazarlardan } \\
\text { müşterilere ulaşma- } \\
\text { mıza katkı sağlar }\end{array}$ & 4 & 9,1 & 5 & 11,4 & 16 & 36,4 & 10 & 22,7 & 9 & 20,5 & 44 & 100 \\
\hline $\begin{array}{l}\text { 7/24 alım-satım ya- } \\
\text { pabilmenin } \\
\text { işletmelere fayda } \\
\text { sağlayacağını düşü- } \\
\text { nüyorum }\end{array}$ & 2 & 4,5 & 4 & 9,1 & 9 & 20,05 & 12 & 27,3 & 17 & 38,6 & 44 & 100 \\
\hline
\end{tabular}


Tablo 4 'te tespit edilen bulgulara göre ticari faaliyetlerinde e-ticareti hiç kullanmayan girişimcilerin \% 41'i gelecek beş y1l içerisinde girişimciliğin e-ticarete bağımlı hale geleceğini büyük oranda kabul etmekteyken \% $31,8^{\prime}$ inin ise bu konuda çekimser oldukları görülmektedir. Bu hususta katılımclara yöneltilen ikinci ifade "e-ticaret sayesinde iş yapma hızı artmaktadır" olmuştur. Tablo 4'teki bulgulara göre araştırmaya katılan girişimcilerin \% 68,2'si e-ticaretin iş yapma hızını arttırdığını kabul etmektedir. Yine e-ticaret faaliyetlerinden hiç faydalanmayan girişimcilerin \% 72,7'si sipariş, tedarik, ödeme gibi süreçlerin e-ticaret yoluyla daha hızlı gerçekleştiğini kabul etmektedirler. Bu hususta katılımcılara yöneltilen diğer bir ifade ise "e-ticaret sayesinde müşteri hizmetleri iyileşmektedir" olmuştur. Söz konusu katılımcıların \% 56,8'si e-ticaretin müşteri hizmetlerini iyileştirdiğini kabul etmektedir. E-ticaret faaliyetlerini iş yaşamına hiç yansıtmamış girişimcilerin "e-ticarete yapılan yatırım, işletmelerin bilinirliğini artırmak açısından çok önemlidir" ifadesine yönelik görüşlerinin analizi neticesinde elde edilen bulgulara göre girişimcilerin $\% 52,2$ 'si eticarete yapılan yatırımın, işletmelerin bilinirliğini artırmak açısından çok önemli olduğunu kabul etmektedirler.

Araştırma kapsamında yapılan analizlere göre e-ticaret yapmayan girişimcilerin \% 56,8'inin, e-ticaretin küresel pazarlara ulaşmayı önemli ölçüde kolaylaştırdığı ifade etmektedirler. Katılımcılara yöneltilen diğer bir ifade olan "e-ticaret işletmelere rekabet üstünlügü sağlamaktadır" ifadesine verilen cevapların analizinden elde edilen bulgulara göre katılımcıların \% 50'si e-ticaretin rakiplerle mücadelede önemli avantajlar sağladığını savunmaktadırlar. Yine söz konusu katılımcıların \% 50'sinin e-ticaretin ulusal pazarlarda yeni müşterilere ulaşmada, $\% 43,2$ 'sinin ise uluslararası müşterilere ulaşmada önemli oranda katkı sağladığını kabul ettikleri tespit edilmiştir.

E-ticaret yapmayan girişimcilere yöneltilen son ifade ise "7/24 alımsatım yapabilmenin işletmelere fayda sağlayacağını düşünüyorum" olmuştur. Tablo 4'e göre söz konusu girişimcilerin \% 65,9'u kesintisiz hizmet vermeye fırsat veren e-ticaret faaliyetlerinin işletmelere önemli avantajlar sağladığını kabul etmektedirler.

Araştırmanın ikinci kısmı e-ticaret yapan girişimcilerin e-ticaret faaliyetlerini kullanmaya iten nedenleri tespit etmeye yönelik analizlerden oluşmaktadır. Araştırma kapsamında katılımcılara katılma düzeylerini 
belirtmeleri istenen 7 farklı ifade verilmiştir. E- ticaret faaliyetlerini aktif olarak kullanan girişimcilerin söz konusu ifadelere katılım düzeylerinin analizi neticesinde elde edilen bulgular Tablo 5'te gösterilmiştir.

Tablo 5. Girişimcileri e-ticaret kullanmaya iten nedenler

\begin{tabular}{|c|c|c|c|c|c|c|c|c|c|c|c|c|}
\hline \multirow{3}{*}{$\begin{array}{l}\text { Girişimcileri e-ti- } \\
\text { caret kullanmaya } \\
\text { iten nedenler } \\
\text { Mevcut } \\
\text { müşterilerin teşviği / } \\
\text { baskısı }\end{array}$} & \multicolumn{2}{|c|}{ 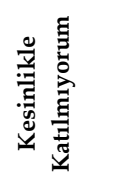 } & \multicolumn{2}{|c|}{ 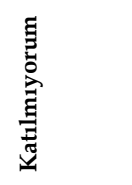 } & \multicolumn{2}{|l|}{ 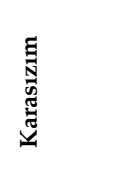 } & \multicolumn{2}{|c|}{ 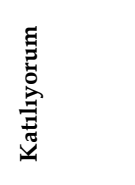 } & \multicolumn{2}{|c|}{ 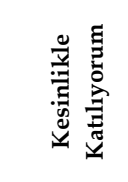 } & \multicolumn{2}{|c|}{$\frac{\Xi}{\frac{\pi}{2}}$} \\
\hline & 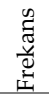 & $\stackrel{0}{0}$ & 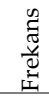 & ्ְ̃ & 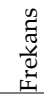 & 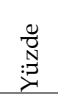 & 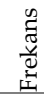 & 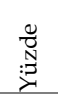 & 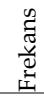 & 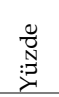 & 䒕 & $\begin{array}{l}\stackrel{\mathbb{N}}{N} \\
:\end{array}$ \\
\hline & 7 & 22,5 & 10 & 32,3 & 3 & 9,7 & 9 & 29,0 & 2 & 6,5 & 31 & 100 \\
\hline $\begin{array}{l}\text { Rekabet } \\
\text { baskısı/Rakiplerden } \\
\text { geride } \\
\text { kalmamak }\end{array}$ & 5 & 16,1 & 4 & 12,9 & 5 & 16,1 & 9 & 29,0 & 8 & 25,8 & 31 & 100 \\
\hline $\begin{array}{l}\text { Müşteri } \\
\text { hizmetlerini } \\
\text { geliştirmek }\end{array}$ & 3 & 9,7 & 3 & 9,7 & 2 & 6,4 & 11 & 35,5 & 12 & 38,7 & 31 & 100 \\
\hline $\begin{array}{l}\text { Müşterilerle } \\
\text { diyaloğa girmek }\end{array}$ & 5 & 16,1 & 3 & 9,7 & 2 & 6,4 & 11 & 35,5 & 10 & 32,2 & 31 & 100 \\
\hline $\begin{array}{l}\text { İş maliyetlerini } \\
\text { azaltmak }\end{array}$ & 3 & 9,7 & 8 & 25,8 & 5 & 16,1 & 5 & 16,1 & 10 & 32,2 & 31 & 100 \\
\hline $\begin{array}{l}\text { Tedarikçilerin } \\
\text { Teşviği / Baskısı }\end{array}$ & 7 & 22,5 & 5 & 16,1 & 4 & 12,9 & 7 & 22,5 & 8 & 25,8 & 31 & 100 \\
\hline $\begin{array}{l}\text { Küresel } \\
\text { pazarlara erişme }\end{array}$ & 2 & 6,4 & 5 & 16,1 & 6 & 19,4 & 9 & 29,0 & 9 & 29,0 & 31 & 100 \\
\hline
\end{tabular}

Tablo 5'e göre e-ticaret yapan girişimcilerin $\% 54,8$ ' $\mathrm{i}$ "mevcut müşterilerin teşviği/baskısı" ifadesinin e-ticaret yapmaya iten bir neden olmadığını savunmaktadırlar. Ayrıca söz konusu katılımcıların \%55,7'sinin rakiplerinden geri kalmamak veya bu konuda rakip baskısını hissetmeleri nedeniyle e-ticarete yöneldikleri bulgulanmıştır. Benzer bir durumun “Tedarikçilerin Teşviği/Baskısı" ifadesinde de var olduğu görülmektedir. Tabloya göre katılımcıların \% 48,3'ü e-ticaret yapma nedenlerinde tedarikçilerin rol aldığını belirtmektedirler. Girişimcileri e-ticaret yapmaya iten en önemli nedenler olarak müşteri hizmetlerini geliştirmek $(\% 74,2)$, 
müş̧terilerle diyaloğa girebilmek $(\% 67,7)$ ve küresel pazarlara erişme $(\%$ $58,0)$ olduğu tespit edilmiştir.

Araştırmanın üçüncü kısmı e-ticaret yapan girişimcilerin e-ticaret kullanmanın sağladığı faydaları ölçmeye yönelik analizlerden oluşmaktadır. Araştırma kapsamında katılımcılara katılma düzeylerini belirtmeleri istenen 9 farklı ifade verilmiştir. E- ticaret faaliyetlerini aktif olarak kullanan girişimcilerin söz konusu ifadelere katılım düzeylerinin analizi neticesinde elde edilen bulgular Tablo 6' da gösterilmiştir.

Tablo 6. E-ticaretin girişimcilere sağladı̆̆ı faydalar

\begin{tabular}{|c|c|c|c|c|c|c|c|c|c|c|c|c|}
\hline \multirow{2}{*}{$\begin{array}{l}\text { E-ticaretin } \\
\text { girişimcilere } \\
\text { sağladığ1 } \\
\text { faydalar }\end{array}$} & \multicolumn{2}{|c|}{ 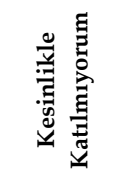 } & \multicolumn{2}{|c|}{ 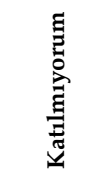 } & \multicolumn{2}{|c|}{ 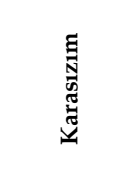 } & \multicolumn{2}{|c|}{ E } & \multicolumn{2}{|c|}{ 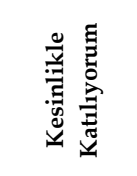 } & \multicolumn{2}{|c|}{ 完 } \\
\hline & 胥 & 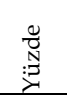 & 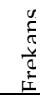 & 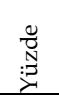 & 䒕 & $\begin{array}{l}\stackrel{8}{0} \\
\dot{N} \\
\end{array}$ & 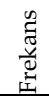 & \begin{tabular}{l}
$\stackrel{\otimes}{0}$ \\
\multirow{2}{*}{}
\end{tabular} & 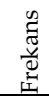 & \begin{tabular}{l}
$\stackrel{\theta}{0}$ \\
\multirow{2}{*}{}
\end{tabular} & है & \begin{tabular}{l}
8 \\
\multirow{N}{*}{} \\
\multirow{2}{*}{}
\end{tabular} \\
\hline $\begin{array}{l}\text { Çalışma saatlerimizin } \\
\text { esnemesine } \\
\text { sağladı }\end{array}$ & 5 & 16,1 & 7 & 22,5 & 6 & 19,4 & 10 & 32,2 & 3 & 9,7 & 31 & 100 \\
\hline $\begin{array}{l}\text { Yurt içinden yeni } \\
\text { müşteriler bulmamıı } \\
\text { sağladı }\end{array}$ & 3 & 9,7 & 2 & 6,5 & 4 & 12,9 & 16 & 51,6 & 6 & 19,4 & 31 & 100 \\
\hline $\begin{array}{l}\text { Yurt dışından yeni } \\
\text { müşteriler bulmamıza } \\
\text { yardımcı oldu }\end{array}$ & 5 & 16,1 & 6 & 19,4 & 5 & 16,1 & 11 & 35,5 & 4 & 12,9 & 31 & 100 \\
\hline $\begin{array}{l}\text { Kişiye özel hizmetler } \\
\text { sunmamızı sağlar }\end{array}$ & 5 & 16,1 & 6 & 19,4 & 6 & 19,4 & 8 & 25,8 & 6 & 19,4 & 31 & 100 \\
\hline $\begin{array}{l}\text { Müşterilerle daha kolay } \\
\text { diyaloğa girmemizi } \\
\text { sağladı }\end{array}$ & 3 & 9,7 & 2 & 6,5 & 5 & 16,1 & 13 & 41,9 & 8 & 25,8 & 31 & 100 \\
\hline $\begin{array}{l}\text { Personelin çalışma saat- } \\
\text { lerinden tasarruf yap- } \\
\text { mamızı sağladı }\end{array}$ & 6 & 19,4 & 7 & 22,5 & 8 & 25,8 & 6 & 19,4 & 4 & 12,9 & 31 & 100 \\
\hline $\begin{array}{l}\text { Yeni tedarikçiler bul- } \\
\text { mamızı sağladı }\end{array}$ & 5 & 16,1 & 5 & 16,1 & 3 & 9,7 & 13 & 41,9 & 5 & 16,1 & 31 & 100 \\
\hline $\begin{array}{l}\text { Daha iyi satın alma } \\
\text { şartları elde ettik }\end{array}$ & 5 & 16,1 & 1 & 3,2 & 9 & 29 & 8 & 25,8 & 8 & 25,8 & 31 & 100 \\
\hline $\begin{array}{l}\text { Etkili reklam ve marka } \\
\text { hizmeti oluşturmamızı } \\
\text { sağladı }\end{array}$ & 3 & 9,7 & 2 & 6,4 & 4 & 12,9 & 14 & 45,1 & 8 & 25,8 & 31 & 100 \\
\hline
\end{tabular}


Tablo 6'ya göre e-ticaret yapan girişimciler e-ticaretin işletmelerine en çok "yurt içinden yeni müşteriler bulma" (\% 71) ve "etkili reklam ve marka hizmeti oluşturma" $(\% 70,9)$ konularında fayda sağlamaktadır. Yine tablo 6'ya bakıldığında e- ticaretin "müşterilerle daha kolay diyaloğa girme" (\% 67,7), "yeni tedarikçiler bulma" (\% 58,0) ve "daha iyi satın alma şartları elde etme" $(\% 51,6)$ konularında da önemli faydalar sağladığı görülmektedir. Söz konusu analizlere göre "çalışma saatlerimizin esnemesine katkı" (\% 41,9) ve "personelin çalışma saatlerinden tasarruf yapma" (\% 32,3) konuları girişimcilere en az fayda sağlayan konular olduğu tespit edilmiştir. Tablo 6 ' da yer alan bulgular genel olarak değerlendirildiğinde, e-ticaretin birçok konuda girişimcilere önemli faydalar sağladığı söylenebilir.

\section{Sonuç}

Bilgi ve iletişim teknolojisindeki gelişmeler ile birlikte internetin küresel ve yaygın kullanımı tüketicilerin geleneksel alışveriş davranışlarını değiştirmede önemli bir etki yapmıştır. Tüketicilerin bir kısmı artık kolaylıkla ulaşabildikleri internet ortamından alışveriş yapmaktadır. Bu davranışı gösteren tüketici sayısı her geçen gün artmaya devam etmektedir. Diğer taraftan girişimcilerin de bu duruma duyarsız kalmaması ve geleneksel iş yapma yöntemlerinin yanı sıra elektronik ticaretten de faydalanması kaçınılmaz olmuştur. E-ticaret, girişimcilerin hem ulusal hem de uluslararası ticaret ağına ulaşmasına kolaylıklar sağlayan önemli bir faaliyet alanıdır. Girişimciler e-ticaret sayesinde maliyetlerini azaltabilir, kar oranını arttırabilir, yeni pazarlar ve müşterilere ulaşabilir ve katma değeri yüksek olan yeni iş ve iş süreçleri edinerek işletmesini büyütebilir. $\mathrm{Bu}$ nedenle günümüzde ve gelecekte girişimcilerin başarılı olabilmeleri için e-ticaretin hayati bir rol oynadığını söylemek yanlış olmayacaktır.

$\mathrm{Bu}$ araştırma, e-ticaret yapmayan girişimcilerin e-ticarete yönelik farkındalıkları, e-ticaret yapan girişimcileri e-ticaret yapmaya iten nedenler ile e-ticaretten fayda sağlayıp sağlamadığı üzerine odaklanmıştır. Bu amaçla Aksaray'da faaliyet gösteren girişimcilerden anket yöntemiyle veri toplanmış ve elde edilen veriler SPSS 20.0 programıla analiz edilmiştir. Yapılan analizler neticesinde e-ticaret yapmayan girişimcilerin önemli bir kısmının e-ticaretin avantajlar sağladığını ve girişimcilerin 
başarılı olabilmesi için gelecekte daha da önemli bir yer edineceğini bildikleri tespit edilmiştir. Yine e-ticaret yapan girişimcileri, e-ticaret yapmaya iten en önemli neden olarak müşteri hizmetlerini geliştirmek $(\% 74,2)$, müşterilerle diyaloğa girebilmek $(\% 67,7)$ ve küresel pazarlara erişebilmek (\% 58,0) olduğu tespit edilmiştir. Analizler neticesinde ayrıca girişimciler için e-ticaretin en çok "yurt içinden yeni müşteriler bulma" (\% 71) ve "etkili reklam ve marka hizmeti oluşturma" (\% 70,9) konularında fayda sağladığı tespit edilmiştir.

Araştırmadan elde edilen sonuçlar, e-ticaretin girişimcilere önemli faydalar sağladığı ve e-ticaret yapmayan girişicimlerin de bunun farkında olduklarını göstermektedir. Bu nedenle girişimcilerin e-ticaret yapmaya yönelik yatırımlar yapmaları, yaptıkları yatırımları takip etmeleri ve bu konuda yetkin nitelikli insan kaynağı bulundurmaları gerektiği önerilebilir. Girişimcilerin e-ticaret yapabilmek için gerekli koşulları oluşturması ve e-ticareti işinin bir parçası haline getirebilmesi durumunda varlıklarını sürdürme, ortalamanın üstünde kar elde etme, güçlü bir rakip haline gelme ve büyümesine önemli katkılar sağlayacağı ifade edilebilir. Dolayısıyla Türkiye' de girişimcilerin e-ticarete yönelik yetkinliklerini arttırabilmelerini sağlayacak eğitim ve destek faaliyetlerin gerçekleştirilmesinin gerekli olduğu önerilebilir.

Araştırmamız Aksaray ilinde faaliyet gösteren girişimcilerden oluşan dar kapsamlı bir örneklem ile sadece girişimcilerin e-ticaret durumlarının incelendiği bir perspektifle gerçekleştirilmiştir. $\mathrm{Bu}$ nedenle gelecekte yapılacak araştırmalar için, diş ticaret yapan girişimciler, e-ticarette karşılaşılan problemler, e-ticaret yapmayı engelleyen unsurlar gibi farklı konuları içeren bölgesel veya tüm ülkeyi kapsayacak kapsamlı araştırmalar yapılması önerilir. 


\section{EXTENDED ABSTRACT}

\section{Examining Entrepreneurs Opinions about E-Commerce: The Case of Aksaray \\ * \\ Şefik Özdemir \\ Aksaray University}

Entrepreneurship can be defined as a set of activities that start with the establishment of a business by taking advantage of the opportunities in the environment actively in order to obtain individual benefits and thereafter contribute to the emergence of economic and social benefits. Türkoğlu et al. (2017) define entrepreneurship as "an entrepreneur's undertaking risks and generating goods or services for profit". When the researches in the literature are examined, it is seen that entrepreneurship positively affects employment, new job creation and economic growth (Özdemir et al., 2016, p. 570). The main actor of the entrepreneurship activities is the entrepreneur. Joseph Schumpeter, one of the first names that comes to mind when the subject is entrepreneurship, defines the entrepreneur as innovators who apply changes to markets by creating new combinations. These innovations can be listed as follows (Ahmad and Seymour, 2008, p. 7):

- Development of a new or a higher quality product

- A new production method,

- Opening a new market,

- Use of a new supply source

- Restructuring work or organizational processes

Therefore, Schumpeter's definition makes entrepreneurship equal to business innovation. This means using innovative approaches to identify and exploit market opportunities (Ahmad and Seymour, 2008, p. 8). In other words, it is not enough to ask for something new and different in entrepreneurship activity. The intended innovations should also be put into operation (Özdemir and Kerse, 2018, p. 15). Entrepreneurs are generally individuals who are self-confident, open to change and aim to get highprofit. As a result, it can be said that entrepreneurs are expected to apply 
the innovations that arise after examining both the local and the global business environment. In addition, entrepreneurs are expected to follow innovations that will contribute to their businesses in terms of both cost and profit, and to give importance to any information that can help them find new customers and suppliers. One of the most important activities that make aforementioned positive contributions to the business processes of entrepreneurs is e-commerce.

Emerging towards the end of the 20th century, e-commerce is, for many, a development which is as important as the invention of printing press or the industrial revolution, and is regarded as the greatest technological revolution. They argue that the effects of e-commerce will be much greater than expected (Canpolat, 2001, p. 12). Electronic commerce is a powerful concept and process that changes the basis of human life. It is one of the main criteria of communication in the field of information technology revolution and economy. This way of trade has spread rapidly as it has provided tremendous benefits for man. It can be strongly argued that electronic commerce overcomes most of the limitations of traditional commerce. For example, the form and appearance of traditional trade has changed fundamentally. These changes provide the basis for any decision in the economy. It is possible to reach virtual markets that do not occupy any physical space and allow access and circulation and markets anywhere in the world without leaving the house. Consequently, electronic commerce, which is placed in virtual showcases in uncertain regions of the world and also advertises in virtual networks and gives the opportunity to select and order all the goods that are paid through electronic services, is seen as the miracle of the century (Nanehkaran, 2013, p. 190). E-commerce has caused a radical change in the economic activities of the enterprises. Face-to-face and paper-based business way of the past has been replaced by web-based electronic systems. Thanks to it, entrepreneurs have the opportunity to do business on a global scale and create new creative works without allocating large budgets (Elibol and Kesici, 2004, p. 304).

This research focuses on e-commerce awareness of entrepreneurs that do not use e-commerce, the reasons that push entrepreneurs who already use e-commerce to do it and whether they benefit from e-commerce. For this purpose, data were collected from the entrepreneurs operating in 
Aksaray by survey method and the data were analyzed with SPSS 20.0 program. As a result of the analyzes, it was found that a significant number of entrepreneurs who do not use e-commerce know that e-commerce provides advantages and that it will gain an even more important place in the future for entrepreneurs to be successful. It was also found that the most important reason that pushed e-commerce entrepreneurs to use it was to improve customer service $(74.2 \%)$, to engage in dialogue with customers $(67.7 \%)$ and to access global markets $(58.0 \%)$. As a result of the analysis, it has been found that e-commerce is most beneficial for entrepreneurs in terms of "finding new domestic customers" (71\%) and "creating effective advertising and brand services" (70.9\%).

The results of the research show that e-commerce provides significant benefits to entrepreneurs and entrepreneurs who do not do e-commerce are aware of this. For this reason, it can be suggested that entrepreneurs should invest in e-commerce, follow their investments and have qualified human resources in the field. It can be stated that entrepreneurs will make significant contributions to maintaining their assets, making higher than average profits, becoming a strong competitor and growth provided that they create the conditions for e-commerce and make it a part of their business. Therefore, it can be suggested that it is necessary to carry out training and support activities that will enable entrepreneurs to increase their competence for e-commerce.

The research was carried out with a narrow perspective with the sample of entrepreneurs operating in Aksaray province by examining only the e-commerce status of them. For this reason, it is recommended to carry out a more comprehensive research covering regions or the whole country, involving different topics such as entrepreneurs that operate foreign trade, problems encountered in e-commerce and elements preventing ecommerce.

\section{Kaynakça / References}

Ahmad, N. ve R. G. Seymour (2008). Defining entrepreneurial activity: definitions supporting frameworks for data collection. OECD Statistics Working Paper, Paris: OECD. 17 Nisan 2019 tarihinde http://search.oecd.org/officialdocuments/displaydocumentpdf-/?doclanguage $=$ en\&cote $=$ std/doc(2008) adresinden erişildi 
Akın, H. B. (2005). Yeni ekonomi: Strateji, rekabet, teknoloji yönetimi. Konya: Çizgi Kitabevi

Aksu, M. ve Gürbüz, A. (2018). Türkiye hayvancılık sektöründe e-ticaret engelleri. Journal of History Culture and Art Research, 7(5), 726-735.

Alyoubi, A. A. (2015). E-commerce in developing countries and how to develop them during the introduction of modern systems. Procedia Computer Science, 65, 479-483.

Aslan, Ş., ve Özata, M. (2007). Kobi'lerde bilgi teknolojisi kullanımının, rekabet gücü, yenilikçilik, girişimcilik ve pazarlama kapasitesiyle ilişkileri: Otomotiv sektöründe bir araştırma. Journal Of The Cukurova University Institute Of Social Sciences, 16(2), 15-28.

Aydın, A. (2018). KOBİ yöneticilerinin web tabanlı e-ticaret hakkındaki bilgi düzeyleri ve tutumları: TRB1 Bölgesi Örneği. Bingöl Üniversitesi Iktisadi ve İdari Bilimler Fakültesi Dergisi, 2(1), 65-89.

Bakirtaş, H., ve Tekinşen, A. (2006). E-ticaretin girişimcilik üzerindeki etkileri. Selçuk Üniversitesi Sosyal Bilimler Enstitüsü Dergisi, 16, 125-138

Bellek, M. (2016). Stratejik yönetimde kobi'lerin sürdürülebilir rekabet üstünlüğ̈̈ sağlamasında e-ticaret uygulamaları ve kayseri organize sanayi bölgesinde faaliyet gösteren işletmeler üzerine bir araştırma. Yayınlanmamış Yüksek Lisans Tezi, Hitit Üniversitesi Sosyal Bilimler Enstitüsü, Çorum.

Butler, P. ve Peppard, J. (1998) Consumer purchasing on the internet: Processes and prospects. European Management Journal, 16(5), 600-10.

Canpolat, Ö. (2001). E-ticaret ve Türkiye'deki gelişmeler, Ankara: T.C. Sanayi ve Ticaret Bakanlığı Hukuk Müşavirliği. 20 Nisan 2019 tarihinde http://my.beykoz.edu.tr/serkang/files/2010/12/e-ticaret-veTurkiye.pdf_adresinden erişildi

Coşkun, N. (2004). Elektronik ticaretin gelişiminde temel dinamikler ve gelişimi önündeki engeller. Çukurova Üniversitesi Sosyal Bilimler Enstitüsü Dergisi, 13(2), 243-258.

Daniel, E. M., ve Grimshaw, D. J. (2002). An exploratory comparison of electronic commerce adoption in large and small enterprises. Journal of Information Technology, 17(3), 133-147.

Daniel, E.M., Wilson, H.N. ve Myers, A. (2002) Adoption of e-commerce by SMEs in the UK: towards a stage model. International Small Business Journal, 20(3), 253-270. 
Delone, W. H., ve Mclean, E. R. (2004). Measuring e-commerce success: Applying the DeLone \& McLean information systems success model. International Journal of electronic commerce, 9(1), 31-47.

Dutta, S. and Evrard, P. (1999) Information technology and organisation within European small enterprises. European Management Journal, 17(30), 239-51.

Elibol, H., ve Kesici, B. (2004). Çağdaş işletmecilik açisindan elektronik ticaret. Selçuk Üniversitesi Sosyal Bilimler Enstitüsü Dergisi, 11, 303-329.

Falk, M., ve Hagsten, E. (2015). E-commerce trends and impacts across Europe. International Journal of Production Economics, 170, 357-369.

Gökçen, H. (2007) Yönetim bilgi sistemleri. Ankara:Palme Yayıncılık.

Hussain, A. (2003). E-Commerce and Beyond: Opportunities for developing country SMEs. International Trade Forum, no. 4. 29 Nisan 2019 tarihinde http://www.intracen.org/article/E-Commerce-and-BeyondOpportunities-for-developing-country-SMEs/ adresinden erişildi.

İşler, D. B. (2008). Rekabetçi avantaj yaratma çerçevesinde kobi'lerde e-ticaret ve e-ticaretin stratejik kullanımı. Süleyman Demirel Üniversitesi İktisadi ve İdari Bilimler Fakültesi Dergisi, 13(3), 277-291.

Kantarcı, Ö., Özalp, M., Sezginsoy, C., Özaşkınlı, O., ve Cavlak, C. (2017). Dijitalleşen dünyada ekonominin itici gücü: E-ticaret. İstanbul: TUSIAD Yayınları,

Kurnia, S., Choudrie, J., Mahbubur, R. M., ve Alzougool, B. (2015). E-commerce technology adoption: A Malaysian grocery SME retail sector study. Journal of Business Research, 68(9), 1906-1918.

Marangoz, M. (2011). Girişimciler için sınırsız ticaret: E-ticaret, Girişimcilik ve Kalkınma Dergisi, 6 (1), 181 - 201

Molla, A., ve Heeks, R. (2007). Exploring e-commerce benefits for businesses in a developing country. The Information Society, 23(2), 95-108.

Nanehkaran, Y. A. (2013). An introduction to electronic commerce. International journal of scientific \& technology research, 2(4), 190-193.

Özdemir Ş. ve Kerse G. (2018). Girişimcilikte başarının anahtarı: Nitelikli iş fikri geliştirme. Konya:Eğitim Yayınevi.

Özdemir, Ş., Yılmaz, N., Arsu, T., ve Polat, Y. (2016). A review on entrepreneurship education in Turkey Türkiye'de girişimcilik eğitimi üzerine bir inceleme. Journal of Human Sciences, 13(1), 569-581. 
Özeroğlu, A. C. (2018). Girişimcilik faaliyetlerinde e ticaret uygulamaları: inovasyon ve dijital girişimcilik. Yayınlanmamış Yüksek Lisans Tezi. İstanbul Gelişim Üniversitesi Sosyal Bilimler Enstitüsü. İstanbul

Poon, S., ve Jevons, C. (1997). Internet-enabled international marketing: a small business network perspective. Journal of Marketing Management, 13(1-3), 29-41.

Premkumar, G. ve Robers, M. (1999) Adoption of new information technologies in rural small businesses. The International Journal of Management Science (OMEGA), 27, 467-84.

Qasim, D., Mohammed, A. B., ve Liñán, F. (2018). The role of culture and gender in e-commerce entrepreneurship: Three Jordanian Case studies. In Entrepreneurship Ecosystem in the Middle East and North Africa (MENA) (p. 419-432). Springer, Cham.

Rahayu, R., ve Day, J. (2015). Determinant factors of e-commerce adoption by SMEs in developing country: evidence from Indonesia. Procedia-Social and Behavioral Sciences, 195, 142-150.

Ray, S. Jeffrey. (2011). Leveling e-commerce opportunities for developing countries. 29 Nisan 2019 tarihinde https://www.researchgate.net/publication/256026445_Leveling_E-Commerce_Opportunities_for_Developing_Countries_adresinden erişildi.

Sarısakal, M. N., ve Aydın, M. A. (2003). E-ticaretin yeni yüzü mobil ticaret. Journal of Aeronautics and Space Technologies, 1(2), 83-90.

Sebora, T. C., Lee, S. M., ve Sukasame, N. (2009). Critical success factors for ecommerce entrepreneurship: an empirical study of Thailand. Small Business Economics, 32(3), 303-316.

Türkoğlu, T., Tetik, S., ve Açıkgöz, A. (2017). Meslek yüksekokulu öğrencilerinin sosyo-demografik özellikleri ile girişimci kişilik özellikleri arasındaki ilişkinin araştırılması. Journal Of Yaşar University, 12(45), 76-92.

Ueasangkomsate, P. (2015). Adoption e-commerce for export market of small and medium enterprises in Thailand. Procedia-Social and Behavioral Sciences, 207, 111-120.

Ulukan, G. (2018). TÜBİSAD'ın raporuna göre e-ticaret hacmi yüzde 37 büyüyerek 42,2 milyar TL'ye ulaştı. Webrazzi. Erişim tarihi: 21 Nisan 2019 tarihinde https://webrazzi.com/2018/05/22/tubisadin-raporunagore-e-ticaret-hacmi-yuzde-37-buyuyerek-422-milyar-tlye-ulasti/ adresinden erişildi 
Yaralı, E. S., ve Kırık, A. M. (2017). Türkiye'de facebook üzerinden e-ticaret uygulamaları: Tesbihane ve Çaykur örneği'. The Journal of Academic Social Science Studies, 55, 525-542.

\section{Kaynakça Bilgisi / Citation Information}

Özdemir, Ş. (2019). Girişimcilerin e-ticarete yönelik görüşlerinin incelenmesi: Aksaray ili örneği.OPUS-Uluslararası Toplum Araştırmaları Dergisi, 13(19), 1502-1527. DOI: 10.26466/opus. 567860 